\title{
Humor Translation Revisited: The Case of Woody Allen's “Annie Hall” Subtitled into Persian
}

\author{
Sajjad Kianbakht \\ IAU South Tehran Branch, Iran
}

Received: 26-07-2015

Accepted: 08-09- 2015

Published: 31-10- 2015

doi:10.7575/aiac.ijclts.v.3n.4p.27

URL: http://dx.doi.org/10.7575/aiac.ijclts.v.3n.4p.27

\begin{abstract}
The present study is an attempt to investigate the subtitling strategies adopted in Persian translation of humor of Woody Allen's "Annie Hall" and to determine which strategy was utilized more frequently than others. The study is a descriptive comparative content analysis on the basis of the dialogues and the corresponding subtitles from Woody Allen's "Annie Hall". The theoretical framework of the present study was based on Henrik Gottlieb's (2001) classifications of subtitling strategies. The results of the study showed that the most frequent strategy was transfer. The high frequency of transfer strategy means that the Iranian subtitlers transferred the dialogues of the original film into Persian in the most comprehensible and natural way possible.
\end{abstract}

Keywords: Audiovisual Translation (AVT), Humor, Subtitling, Translation Strategy

\section{Introduction}

In the world of high technology and mass media, the overgrowing need for audiovisual translation calls for the academic investigation of this special type of translation. Specifically contemporary mass communication has created a new situation in which translation plays an essential role. Diaz Cintas $(2009$, p.6) believes that "it is evident that the way in which we interact has changed and is still constantly changing and these changes create new communication needs". He also considers "audiovisual translation" (AVT) as a powerful activity, which is a significant form of intercultural communication.

Humor, another major variable of the present study, is an essential part of everyday communication and an important component of innumerable literary works, films and of art in general. It is not only rooted in a specific cultural and linguistic context, but it is also an indispensable part of intercultural communication and mass entertainment.

The ability to comprehend, appreciate and produce humorous elements is central to human culture and social interaction, and hence the area of humor and its translation merits scientific study.

Considering the above perspectives and the overgrowing importance of audiovisual translation and "the dearth of serious work on humor translation in translation studies ..." according to Vandaele (2002c), made the investigation of subtitling strategies adopted in translation of humor of Woody Allen's "Annie Hall" the subject of the present study. The researcher carried out a descriptive comparative content analysis of the dialogues and the corresponding subtitles of Woody Allen's aforementioned film. The researcher employed the typology of subtitling strategies recapitulated by Henrik Gottlieb (2001, pp.1010) as a theoretical framework, in order to find out and describe what the subtitler has done in every segment of the film in which the use of humor is present.

\section{Theoretical Background}

Subtitling has been defined by many authorities in the field as an evidence of "the rendering in a different language of verbal messages in filmic media, in the shape of one or more lines of written text, presented on the screen in sync with the original verbal message" (Gottlieb, 2004, p.15).

Traditionally, it is believed that there are two types of subtitles: interlingual subtitles, which imply transfer from a SL into a TL, and intralingual subtitles, for which there is no change of language (Díaz Cintas, 2003). According to Gottlieb (2004), interlingual subtitling, having societal and language-political implications, is instrumental in improving reading skills, boosting foreign language skills, facilitating easy and cheap international program exchange, and cementing the dominance of English.

Gottlieb (2001, pp.1010) further believes that to assess the quality of a specific subtitling, the rendering of each verbal segment of a film must be analyzed with regard to its stylistic and semantic values. Accordingly he has proposed ten translation strategies for subtitling films, as follows:

1. Expansion is used when the original text requires an explanation because of some cultural nuance not retrievable in the target language. 
2. Paraphrase is resorted to in cases where the phraseology of the original cannot be reconstructed in the same syntactic way in the target language.

3. Transfer refers to the strategy of translating the source text completely and accurately.

4. Imitation maintains the same forms, typically in the case of names of people and places.

5. Transcription is used in those cases where a term is unusual even in the source text, for example, the use of a third language or nonsense language.

6. Dislocation is adopted when the original text employs some sort of special effect, e.g., a silly song in a cartoon film where the translation of the effect is more important than the content.

7. Condensation that is, the shortening of the text in the least obtrusive way possible, seems to be the typical strategy used in translation of subtitles.

8. Decimation is an extreme form of condensation where perhaps for reasons of discourse speed, even potentially important elements are omitted.

9. Deletion refers to the total elimination of parts of a text.

10. Resignation describes the strategy adopted when no translation solution can be found and meaning is inevitably lost.

He claims that these strategies can be found in translation of different genres including humor, which is an integral part of western culture and films. Humor involves different modes and falls into different groups if viewed from different angles and for different purposes. It has been categorized into certain types by different scholars. Raphaelson-West (1989, p.130) divided humor into three groups: linguistic humor like puns and word plays, cultural humor such as ethnic ones and universal humor, the unexpected, for example. Similarly, Schmitz (2002, p. 89) has categorized humor into three types: 1) universal humor, 2) culture-based humor, and 3) language-based humor.

Schmitz (2002) has defined the universal type of humor as reality-based humor induced mainly by the context and the general functioning of the world. He has explained the second type or culture-based humor as being embedded in the source culture and finally he has proposed linguistic type as word-based humor produced by linguistic devices such as idioms, slangs, and wordplays and so on and so forth.

\section{Methodology}

This study, which falls under the classification of subtitling strategies, followed Gottlieb's model as the theoretical framework. According to Gottlieb (2001, p.1010), to assess the quality of a specific subtitling, the translation of each verbal segment of film must be analyzed according to its stylistic and semantic values.

\subsection{Source Material}

The source material of the present study is the dialogues from Woody Allen's film "Annie Hall" and its corresponding Persian subtitles. This film is one of Woody Allen's masterpieces as one of the greatest humorists ever seen. Annie Hall is an American romantic comedy film directed by Woody Allen from a screenplay he co-wrote with Marshall Brickman. The film is a major turning point in Allen's career which unlike his other comedies introduced a level of seriousness.

\subsection{Procedure}

The data collection and analysis of the present study took place in three phases:

In the first stage the researcher identified the humorous elements in the films based on Schmitz' categorization of humor (2002), i.e. universal humor, culture-based humor, and language-based humor mentioned above.

The second step was to prepare the transcriptions of the dialogues of the film as well as their corresponding subtitles in Persian.

The next stage was the analysis and comparison of the dialogues in English and their relevant Persian renderings in order to find out the answers to the research questions. For the analysis of the subtitling of the corpora, Gottlieb's aforementioned recapitulation of the classification of subtitling strategies was employed (2001, p.1010).

\section{Findings}

Data analysis was one of the qualitative steps taken separately for each humorous piece in this research. In order to conduct this part of the study, the researcher used Table 1 below which was designed by Jose Martinez-Sierra (2005, p. 293), adapted it for the purposes of the present research.

Fifty five humorous elements were detected and analyzed in the source text during this research. In the following tables the Persian versions are given according to UN system of transliteration. Due to the space limitations of this article, only three examples, one for each top three strategies with the highest frequency have been presented here. These three strategies together make up 33 examples with $59.99 \%$ of the total frequencies; those interested in this research may contact the author for the full version of the research. 
Table 1. Details of Data Analysis Utilizing Martinez Model.

\begin{tabular}{ll}
\hline Film & Annie Hall. \\
\hline Context & In the opening lines of the film Alvy starts telling some jokes. \\
\hline Source Version & $\begin{array}{l}\text { Alvy: "I would never wanna belong to any club that would have someone like me for } \\
\text { a member." }\end{array}$ \\
\hline Humorous Load & Universal. \\
\hline Persian Subtitling & $\begin{array}{l}\text { Alvy: Hargez hazer nīstam 'ozve kūlūpī besham ke kasī mesle man row be 'ozvìyat } \\
\text { bepazìreh. }\end{array}$ \\
\hline Subtitling Strategy & Transfer.
\end{tabular}

This explanation is applied to all the following tables in this section.

Table 2

\begin{tabular}{ll}
\hline Film & Annie Hall. \\
\hline Context & It's a beautiful sunny day in Central Park. People are sitting on benches, others \\
& strolling, some walking dogs. Alvy and Annie observe the scene before them. An \\
older man with a pink coat and woman walk before them.
\end{tabular}

\begin{tabular}{ll}
\hline Source Version & Alvy: Look, look at that guy. \\
Annie: M'hm. \\
Alvy: There's-there's-there's-there's Mr. When-in-the-Pink, Mr. Miami Beach, there, \\
you know? He's the latest! Just came back from the gin rummy finals. He placed \\
third. \\
Cultural. \\
\hline Humorous Load & $\begin{array}{l}\text { Alvy: Ūn yarū row negā kon. Taraf che bādī be ghabghabesh andākhteh bā ūn kote sūratīsh. Engār tāzeh } \\
\text { bēzīye Jīn rāmīsh row tāmūm kardeh.Va hālā dāreh hāl mīkoneh. }\end{array}$
\end{tabular}

Subtitling Strategy Dislocation.

Table 3

\begin{tabular}{|c|c|}
\hline Film & Annie Hall. \\
\hline Context & $\begin{array}{l}\text { They're in a Hollywood Christmas party, complete with music, circulating waiters, } \\
\text { holding out trays of drinks. Rob and Alvy observe the guests. Rob nods his head } \\
\text { toward a tall peachy woman dressed all in white with the visible panty line, meanwhile } \\
\text { the woman in white starts walking toward them. }\end{array}$ \\
\hline Source Version & $\begin{array}{l}\text { Rob: If she comes over here, Max, my brain is going to turn into guacamole. } \\
\text { Alvy: I'll handle it. Hi. }\end{array}$ \\
\hline Humorous Load & Cultural. \\
\hline Persian Subtitling & $\begin{array}{l}\text { Rob: Ageh ūmad īnvar, say kon khūnsard bāshī. } \\
\text { Alvy: Man hallesh mīkonam. }\end{array}$ \\
\hline Subtitling Strategy & Resignation. \\
\hline
\end{tabular}

After analyzing the data, the summary of the findings are presented in the form of a descriptive table for the film, which shows the frequency and percentage of the ten subtitling strategies. Table 4 specifies the frequency and percentage of different subtitling strategies in the film under investigation. 
Table 4. Frequency and Percentage of Different Subtitling Strategies in the Film

\begin{tabular}{lll}
\hline Strategies & Frequency \& Percentage & Annie Hall \\
\hline \multirow{2}{*}{ Transfer } & Frequency & 15 \\
\cline { 2 - 3 } & Percentage & 27.27 \\
\hline Dislocation & Frequency & 10 \\
\cline { 2 - 3 } & Percentage & 18.18 \\
\hline Resignation & Frequency & 8 \\
\cline { 2 - 3 } & Percentage & 14.54 \\
\hline Imitation & Frequency & 6 \\
\cline { 2 - 3 } & Percentage & 10.90 \\
\hline Condensation & Frequency & 5 \\
\cline { 2 - 3 } & Percentage & 9.09 \\
\hline Paraphrase & Frequency & 4 \\
\cline { 2 - 3 } & Percentage & 7.27 \\
\hline Expansion & Frequency & 3 \\
\cline { 2 - 3 } & Percentage & 5.45 \\
\hline Transcription & Frequency & 2 \\
\cline { 2 - 3 } & Percentage & 3.63 \\
\hline Deletion & Frequency & 1 \\
\cline { 2 - 3 } & Percentage & 1.81 \\
\hline Decimation & Frequency & 1.81 \\
\cline { 2 - 3 } & Percentage & \\
\hline
\end{tabular}

The analysis of the results shows that different subtitling strategies have been adopted by the translators in rendering humorous elements. The frequency of identified strategies from the highest to the lowest are as follows:

Transfer is the most frequently used strategy in all three humor categories with 15 hits (27.27\%); dislocation 10 hits (18.18\%); resignation 8 hits $(14.54 \%)$; imitation 6 hits $(10.90 \%)$; condensation 5 hits $(9.09 \%)$; paraphrase 4 hits (7.27\%); expansion 3 hits (5.45\%); transcription 2 hits (3.36\%); deletion 1 hit (1.81\%); decimation 1 hit (1.81\%).

\section{Discussion}

Content analysis of the original Woody Allen's film and the subtitled version plus the statistical analysis of the results in the present study lead to the following conclusions:

Different subtitling strategies have been applied by the translators in rendering humorous elements; the identified strategies in the order from the most frequently used to the least frequently used ones are as follows:

Transfer, dislocation, resignation, imitation, condensation, paraphrase, expansion, transcription, deletion and decimation. Results show that transfer subtitling strategy is the most frequently used strategy in all three humor categories with 15 hits. This means that the Iranian subtitlers tried their best to transfer the dialogues of the original film into Persian in the most comprehensible and natural way possible.

In universal humor category, where the whole story is to convey the humorous effect and message, and which can be conceived in all cultures and languages, the translation is carried out with the least possible difficulties and in most cases the transfer subtitling strategy has been the first and most frequently used strategy.

In translating cultural humor category, the translator faces two sorts of challenges. The first one is related to rendering cultural notions and concepts and the second one is the linguistic devices used in the original. In this category of humorous discourses, in cases where the culture-bound elements are neutralized or generalized, cultural sense of the original is missed and the translation does not read as humorous as the original.

In subtitling linguistic humor category, the translators are faced with a kind of dilemma. The difficulty arises when the linguistic devices such as puns, play roles in making the discourse humorous. When there is no one to one equivalent in terms of linguistic units and rhetorical devices like puns in TL, the loss of meaning is inevitable. In such cases the humor is missed in translation and the text reads as a neutralized one, subsequently no sense of humor is perceived.

It's worth mentioning that due to the fact that each humorous element is a specific one, different subtitling strategies have been applied even in subtitling of the same humor category and sometimes more than one strategy is used to translate a single humorous element.

Moreover the present study shows that the subtitlers of Woody Allen's films suffer from a number of shortcomings that may be summarized as follows:

(1) Poor knowledge of English is seemingly the source of considerable number of their mistakes (20\% of the cases);

(2) Lack of scientific methods and mastery over subtitling strategies would not allow translators to follow straightforward guidelines in their course of translating humor; 
(3) Ignorance and carelessness toward cultural notions and connotations seem to be the cause of the loss of humorous effects of the original cultural concepts in TT.

Furthermore after scrutinizing Gottlieb's proposed subtitling strategies the researcher detected some pitfalls with his typology. The problem with Gottlieb's strategies is that they give the impression of being clear-cut, scientifically verifiable categories. Under scrutiny, however, they seemed to the researcher to be somehow overlapping and subjective. For example, the line between condensation (described by Gottlieb as "condensed expression, concise rendering") and decimation ("abridged expression, reduced content") (2001) seems rather difficult to draw. In addition, some strategies were found to be awkward (such as imitation, which is used with proper nouns and international greetings), or of low-priority (such as transcription of non-standard elements). Therefore, we may claim that Gottlieb is giving his typology only on the basis of his own personal experience as a subtitler and therefore it is quite possible that different researchers might have problems with his typology.

\section{Acknowledgment}

I would like to express my sincere appreciation to Dr. Esmail Faghih for all his help, support and encouragement.

\section{References}

Baker, M. (Ed.).(1998). Routledge encyclopedia of translation studies. London: Routledge.

Diaz Cintas, J. (2003). Audiovisual translation in the third millennium.In G. Anderman\& M. Rogers (Eds.), Translation today: Trends and perspectives (pp.192-204). Sydney: Multilingual Matters Ltd.

Diaz Cintas, J. (2009). Audiovisual translation: An overview of its potential. In: J.Diaz Cintas (Ed.), New trends in audiovisual translation. Bristol / Buffalo / Toronto: Multilingual Matters. 1-18.

Gottlieb, H. (2001). Anglicism and TV subtitling in an anglified world.In Y. Gambier \& H. Gottlieb (Eds.), Multimedia translation: concepts,practices, and research. Amsterdam: John Benjamins Publishing Company. 249-258.

Gottlieb, H. (2001). Subtitling.In S.-W.Chan \& D.E. Pollard (Eds.), (2001).An Encyclopedia of Translation: ChineseEnglish, English-Chinese. Hong Kong: Chinese Up. 1004-1011.

Gottlieb, H. (2004). Screen Translation. Seven Studies in Subtitling, Dubbing and Voice-over. 4th edition. Copenhagen: University of Copenhagen, Centerfor Translation Studies.

Martinez-Sierra, J. (2005) "Translating Audiovisual Humor. A Case Study", in Henrik Gottlieb (ed.) Perspectives: Studies in Translatology, Copenhagen: Routledge, 289-296.

Raphaelson-West, D. S. (1989) "On the Feasibility and Strategies of Translating Humor", In Meta, Volume 34, Number 1, 1989. Special Issue on Humor and Translation, 128-141.

Schmitz, J.B. (2002). Humor as a pedagogical tool in foreign language and translation courses. Humor, 15(1), 89-113.

Vandaele, J. (2002c) (Re-) Constructing Humour: Meanings and Means. The Linguist, 8(2), 149-172. 